\title{
Association between vitamin $D$ and pressure ulcers in older ambulatory adults: results of a matched case-control study
}

This article was published in the following Dove Press journal:

Clinical Interventions in Aging

| August 201 I

Number of times this article has been viewed

\author{
Usha R Kalava' \\ Stephen S Cha ${ }^{2}$ \\ Paul Y Takahashi ${ }^{1,3}$ \\ 'Department of Internal Medicine, \\ Division of Primary Care Internal \\ Medicine, ${ }^{2}$ Department of \\ Biostatistics, ${ }^{3}$ Kogod Center \\ of Aging, Mayo Clinic, \\ Rochester, MN, USA
}

Correspondence: Paul Y Takahashi Mayo Clinic, Division of Primary Care Internal Medicine, 200 First Street SW, Rochester, MN 55905, USA

Tel +l 5072845944

Fax + I 5072660036

Email takahashi.paul@mayo.edu
Background: Pressure ulcers are common among older adults, but knowledge about nutritional risk factors is still developing. Vitamin D deficiency is common in the elderly population and is required for normal skin proliferation. The role of vitamin $\mathrm{D}$ in pressure ulceration and wound healing is not known. The purpose of this case-control study was to determine the association between vitamin $\mathrm{D}$ levels and pressure ulceration in an older community-dwelling cohort.

Methods: All cases and controls were community-dwelling elderly older than 60 years in a primary care panel in Olmsted County, MN. Pressure ulcer cases were defined clinically. The controls were age-matched and gender-matched to controls without pressure ulceration. The main exposure variable was 25-hydroxyvitamin D levels in both groups. The other exposure variable was the Charlson Comorbidity Index used to measure medical comorbidity. The analysis included univariate and conditional logistic regression for 25 -hydroxyvitamin D levels.

Results: The average (standard deviation) age of the study participants with a pressure ulcer was 80.46 years $( \pm 8.67)$, and the average vitamin D level was $30.92 \mathrm{ng} / \mathrm{mL}( \pm 12.46)$. In univariate analysis, Vitamin D deficiency (levels $<25 \mathrm{ng} / \mathrm{mL}$ ) was associated with pressure ulcers (odds ratio: 1.871, $P=0.0154$ ). Comorbidities of the subjects calculated using the Charlson Comorbidity Index were also associated with pressure ulcers (odds ratio: 1.136, $P<0.001$ ). In the final conditional logistical regression model, the association of Vitamin D and pressure ulcers became nonsignificant after adjustment for comorbid illness.

Conclusion: Medical comorbidities increased the risk of pressure ulceration. Vitamin D deficiency was not an independent risk factor for pressure ulceration, and may be a marker of comorbid illness.

Keywords: pressure ulcer, vitamin D, case-control study, aging, geriatrics

\section{Introduction}

Pressure ulcers represent a common condition seen most often in high-risk populations, such as older patients and those with physical impairment. The epidemiology of pressure ulcers varies considerably by clinical setting, with incidence rates ranging from $0.4 \%$ to $38 \%$ in acute care, $2.2 \%$ to $23.9 \%$ in long-term care, and $0 \%$ to $17 \%$ in home care. ${ }^{1}$ In acute care facilities in the US alone, an estimated 2.5 million pressure ulcers are treated each year. ${ }^{2}$ Pressure ulcers cause morbidity and significant suffering, so there is a strong impetus for action. The development of pressure ulcers after hospitalization can interfere with functional recovery, and may be complicated by pain and infection. Pressure ulcers can contribute to an increased length of hospital stay. ${ }^{3}$ The presence of pressure ulcers is a marker of poor overall prognosis and may contribute to premature 
mortality in some patients. ${ }^{4,5}$ Thus, there is a clear need to understand some of the risk factors for pressure ulceration.

Vitamin D is a fat-soluble nutrient that humans obtain via the diet and by synthesis in the skin upon exposure to ultraviolet B light. The vitamin D receptor was discovered in the mid 1970s. ${ }^{6,7}$ Its presence in a number of body tissues not previously associated with calcium and phosphorus metabolism was discovered by immunochemical measurements and by the accumulation of titrated 1,25dihydroxyvitamin $\mathrm{D}_{3}$ in target nuclei. ${ }^{8}$

Skin is a target of vitamin D action. This has been clearly established by the presence of the vitamin D receptors in keratinocytes, sebocytes, and dermal papilla cells. ${ }^{9-11}$ Vitamin D has been associated with proliferation, differentiation, and immunoregulation of cells. Vitamin D is shown to play a role in terminal differentiation of epidermal cells in vitro. ${ }^{12}$ Vitamin D has some potential role in skin health and maintenance, and hence the interest in the relationship between vitamin $\mathrm{D}$ and pressure ulcers. All the aforementioned studies have focused on wound healing. Unfortunately, there is no evidence in the literature looking specifically at vitamin D and development or healing of pressure ulcers. The association between vitamin D and pressure ulceration is not known. We suspect that there may be a relationship between vitamin $\mathrm{D}$ levels and development of pressure ulcers. The objective of this age-matched and gender-matched case-control study was to determine the association between vitamin D levels and the development of pressure ulcers.

\section{Methods}

\section{Study design}

This was a matched case-control study involving adult outpatients at the Division of Primary Care Internal Medicine, Mayo Clinic, Rochester, MN. This was a nested case-control study of a cohort of individuals with documented vitamin D levels. The Mayo Clinic institutional review board reviewed and approved the protocol. The authors conducted all aspects of the research in this project in accordance with the principles of the Declaration of Helsinki. ${ }^{13}$

\section{Setting}

Mayo is an academic medical center with both faculty physicians and training health care providers. Primary Care Internal Medicine provides primary care to the local residents of Rochester and Olmsted County. Olmsted County had a population of 143,962 in 2009 , with $89 \%$ being White, 4\% Black/African-American, 0.3\% American Indian or Alaska native, 5.4\% Asian, and 3.1\% Hispanic/Latino. ${ }^{14}$ The study period covered March 2001 to December 2010.

\section{Participants}

Participants were adults older than 60 years who were assigned to a Primary Care Internal Medicine care provider during the study period. All the participants were communitydwelling or lived in an assisted living facility within Olmsted County. Residents living within a skilled nursing facility or who did not provide consent for medical record review were excluded.

Cases were subjects who were diagnosed with pressure ulcers from March 2001 through December 2010 and had a vitamin D level available prior to the event. These cases were drawn from a previous cohort of individuals with documented vitamin D levels. Controls were selected from the same cohort who had their vitamin D level available and were matched for age and gender. The diagnosis of pressure ulceration was made clinically by medical providers and was documented in the medical records and/or billed as a pressure ulcer. Patients were matched for both gender and for age \pm 4 years. There was 1:2 matching of cases to controls.

Bias within the study was minimized by including all cases of pressure ulceration with vitamin D levels within the cohort. Matching for age and gender allowed the investigators to reduce the potential effects of these two likely confounders. We further attempted to reduce the bias by adjusting for comorbid medical status using Charlson Comorbidity Index exposure as described below.

\section{Data collection}

Health science research personnel extracted data from the electronic medical records of patients enrolled in the study. The abstractors were blinded to the study hypothesis and were not involved with the analysis or interpretation of the data. Electronic medical records contained all medical diagnosis and demographic information for each patient. The Mayo Clinic maintains an electronic system for clinical use, billing, and medical archives through the Rochester Epidemiology Project. ${ }^{15}$ Using this administrative electronic information, the authors collected the demographics, 25-hydroxyvitamin D levels, and other comorbid health risk factors for cases and controls. The medical provider made the final clinical diagnosis of pressure ulcer in the electronic medical records. All 25-hydroxyvitamin D levels were drawn and available in medical records at the Mayo Clinic. The levels were measured by liquid chromatographytandem mass spectrometry. All comorbid conditions were identified by ICD-9 codes from administrative/billing data. 


\section{Exposure variables}

25-hydroxyvitamin $\mathrm{D}$ was the primary exposure variable of interest. In the clinical laboratory at the Mayo Clinic, a deuterated stable isotope (d3-25-hydroxyvitamin $\mathrm{D})$ is added to a $0.1 \mathrm{~mL}$ serum sample as the internal standard. 25-hydroxyvitamin $\mathrm{D}_{2}, 25$-hydroxyvitamin $\mathrm{D}_{3}$, and the internal standard are extracted with acetone and ethyl acetate. The extracts are then derivatized before being analyzed by liquid chromatography-tandem mass spectrometry using multiple reaction monitoring. 25-hydroxyvitamin $\mathrm{D}_{2}$ and 25-hydroxyvitamin $\mathrm{D}_{3}$ levels are quantified and reported individually and as a sum.

Demographic variables collected included age and gender. Comorbid conditions were identified from administrative/ billing data on the day that the 25-hydroxyvitamin $\mathrm{D}$ levels were obtained. For subjects with multiple 25 -hydroxyvitamin D levels, the last 25-hydroxyvitamin D level was taken into consideration. Patients were dichotomized into normal or low vitamin D levels. According to the medical laboratories at the Mayo Clinic, 25-hydroxyvitamin D levels $25-80 \mathrm{ng} / \mathrm{mL}$ are considered normal, and levels $<25 \mathrm{ng} / \mathrm{mL}$ are considered deficient, with $<10 \mathrm{ng} / \mathrm{mL}$ being considered very deficient ${ }^{16}$ (see Table 1). Subjects having vitamin D levels $<25 \mathrm{ng} / \mathrm{mL}$ were labeled as Group 1 and 25-hydroxyvitamin D levels $>25 \mathrm{ng} / \mathrm{mL}$ were considered normal and labeled as Group 2.

Comorbid medical conditions were identified and given a Charlson Comorbidity Index score. The Charlson Comorbidity Index score predicts the 1-year mortality for a patient who has comorbid conditions such as heart disease, acquired immunodeficiency syndrome, or cancer (a total of 22 conditions). Each condition is assigned a score of 1, 2, 3 , or 6 , depending on the risk of dying associated with the condition. The scores are then summed and given a total score. ${ }^{17,18}$ Table 2 describes the scoring system for the Charlson Comorbidity Index.

\section{Data analysis and statistical methods}

Initial analysis included univariate analysis of 25-hydroxyvitamin D levels and pressure ulcers using conditional logistic

Table I Mayo Clinic medical laboratory reference ranges for total serum 25-hydroxyvitamin $D^{15}$

Severe deficiency $<0 \mathrm{ng} / \mathrm{mL}$

Mild to moderate deficiency $10-24 \mathrm{ng} / \mathrm{mL}$

Optimal $25-80 \mathrm{ng} / \mathrm{mL}$

Possible toxicity $>80 \mathrm{ng} / \mathrm{mL}$

By permission of Mayo Foundations for Medical Education and Research. All rights reserved.
Table 2 Weighted Charlson Comorbidity Index ${ }^{17}$ for comorbidities and age

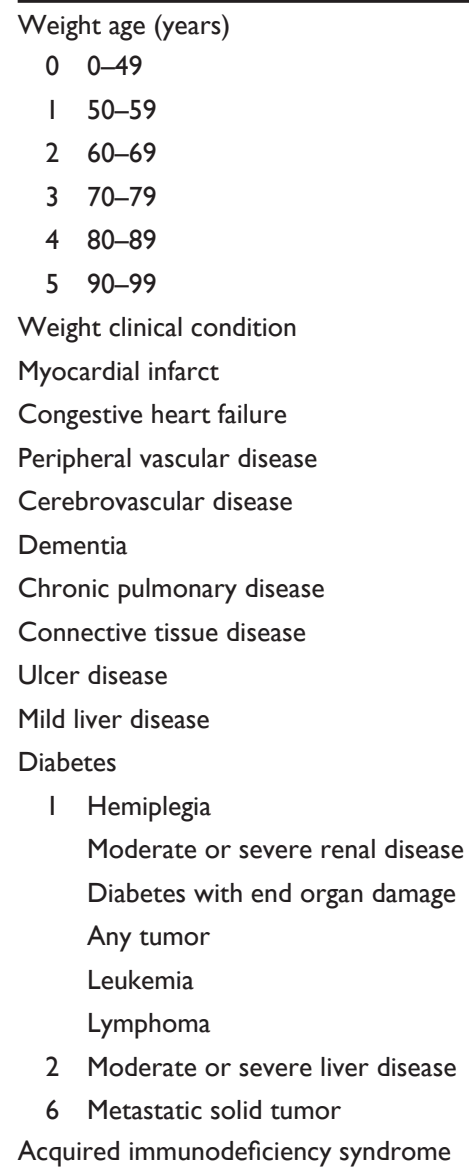

Weight clinical condition

Myocardial infarct

Congestive heart failure

Peripheral vascular disease

Cerebrovascular disease

Dementia

Chronic pulmonary disease

Connective tissue disease

Ulcer disease

Mild liver disease

Diabetes

I Hemiplegia

Moderate or severe renal disease

Diabetes with end organ damage

Any tumor

Leukemia

Lymphoma

2 Moderate or severe liver disease

6 Metastatic solid tumor

Acquired immunodeficiency syndrome

Reprinted from Journal of Chronic Disease, Vol 40, Issue 5, Charlson et al, A new method of classifying prognostic comorbidity in longitudinal studies: Development and validation, 373-383, Copyright (1987), with permission from Elsevier.

regression. Charlson Comorbidity Index and vitamin D levels were also evaluated using conditional logistic regression. The final analysis used multivariate conditional logistic regression analysis with both vitamin $\mathrm{D}$ levels and Charlson Comorbidity Index.

\section{Results}

The initial cohort of individuals with 25-hydroxyvitamin D levels was 1790 patients within the appointed time frame. Of these 1790 individuals, the nested case-control study used all 123 patients with identified pressure ulcers (see Figure 1). These cases were matched for age within 4 years, except for two people. One of the controls matched with an age difference within 5 years and the other within 8 years.

Mean age of patients in the control group was 80.31 years and in cases was 80.46 years. There was no significant difference between the ages in both groups. The descriptive findings between the cases and controls are shown in Table 3 . Of note in the descriptive statistics, there were statistically 


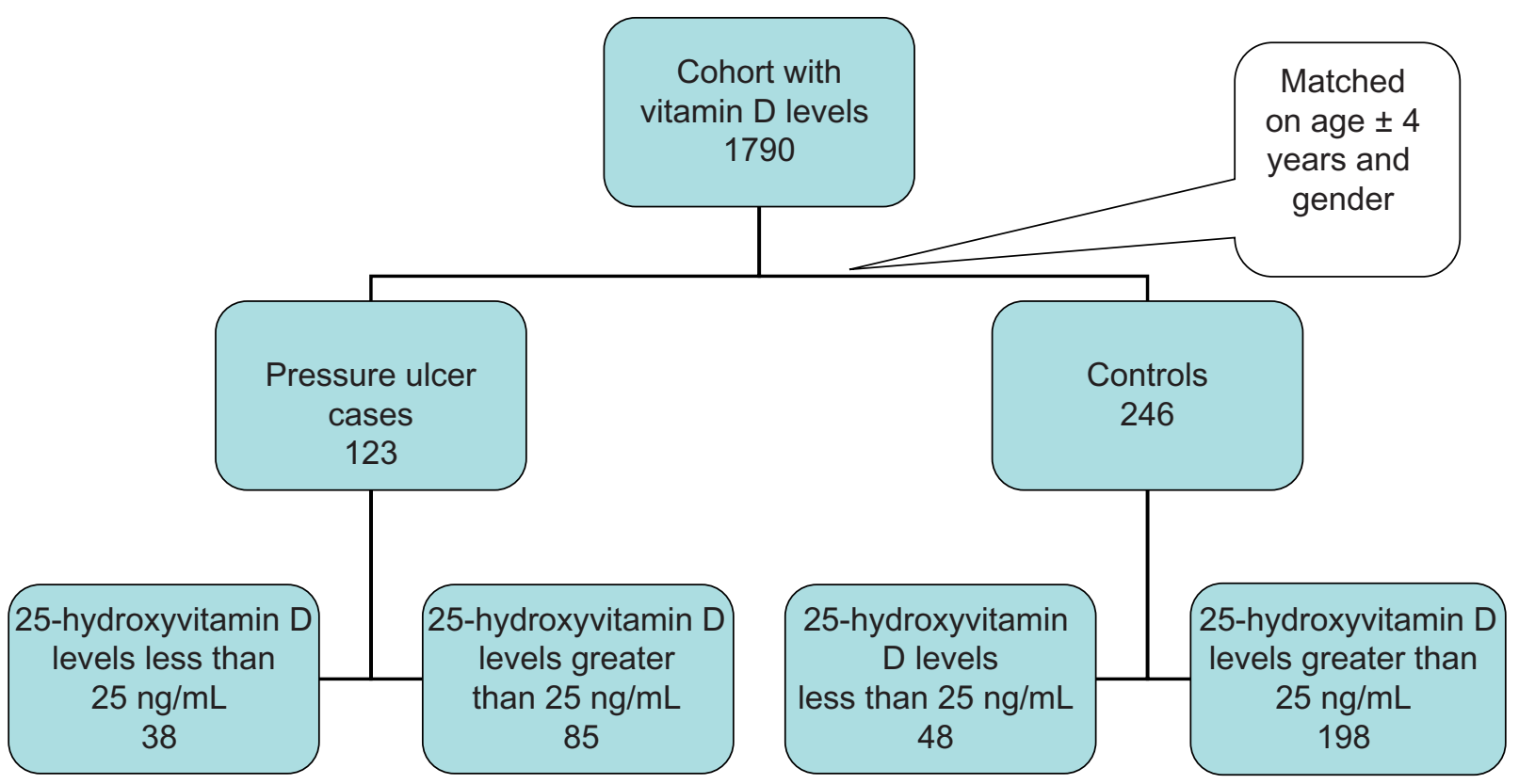

Figure I Flow chart for cases and controls.

significant differences in the comorbid illnesses of diabetes (38\% of cases and $20 \%$ of controls), congestive heart failure ( $54 \%$ of cases and $30 \%$ of controls), and renal disease (57\% of cases and $35 \%$ of controls). The average number of days of follow-up from the vitamin D draw to pressure ulceration or last follow-up was $596.35 \pm 681.52$ days among cases and $1043.93 \pm 625.44$ days among controls.

The mean continuous 25 -hydroxyvitamin D level among cases was $30.9 \mathrm{ng} / \mathrm{mL}$ and among controls was $35.32 \mathrm{ng} / \mathrm{mL}$, with a $P$ value of 0.037 . The mean Charlson Comorbidity Index score was 10.54 among cases and 8.57 among controls, for a $P$ value of $<0.001$. Using dichotomous vitamin D deficiency or normal, $31 \%$ of cases were vitamin D-deficient compared with $20 \%$ of controls who were vitamin D-deficient.

The primary univariate findings are shown in Table 4. Vitamin D deficiency was associated with pressure ulceration (odds ratio [OR]: $1.871, P=0.0154$ ). The Charlson Comorbidity Index score was also associated with pressure ulcers (OR: 1.136, $P<0.001$ ). For every unit increase in Charlson Comorbidity Index, the risk of pressure ulceration increased by $14 \%$.

After initial univariate evaluation, multivariable conditional logistic regression for vitamin D level and comorbidities was performed. The association of continuous 25-hydroxyvitamin D and pressure ulceration became nonsignificant after adjustment using the Charlson Comorbidity Index. Analyzing the data using dichotomous vitamin D deficiency versus normal also found no significant difference between pressure ulcer cases and controls in the model. The Charlson Comorbidity Index remained a significant predictor in the final model (see Table 5).

This was a pilot study to determine the variance of vitamin D levels and pressure ulcers. We found a 0.11 increased risk of vitamin D deficiency in patients with pressure ulcers compared with controls without ulcers. There were 123 pressure ulcer cases. Based upon a sample size of 123 , a power calculation was obtained prior to analysis; 123 pairs had $90 \%$ power to detect a difference in proportions of 0.190 when the proportion of discordant pairs was expected to be 0.450 and the method of analysis was a McNemar's test of equality of paired proportions with a 0.050 two-sided significance level. Thus, this initial pilot study was underpowered to detect a difference in exposure between cases and controls.

\section{Discussion}

In this nested case-control study, Vitamin D deficiency was not different between pressure ulcer cases and age-matched and gender-matched controls after adjusting for comorbid medical conditions. In univariate analysis, vitamin D deficiency (levels $<25 \mathrm{ng} / \mathrm{mL}$ ) was associated with pressure ulceration (OR: 1.871, $P=0.0154$ ). The Charlson Comorbidity Index was also associated with pressure ulcers (OR: 1.136, $P<0.001)$. In the multivariate model, when both exposures were added, the association between vitamin D deficiency 
Table 3 Characteristics of cases with pressure ulcers and control subjects

\begin{tabular}{|c|c|c|c|c|c|c|c|}
\hline \multirow[t]{2}{*}{ Variable } & \multicolumn{2}{|l|}{ Overall } & \multicolumn{2}{|c|}{ Controls } & \multicolumn{2}{|l|}{ Cases } & \multirow[t]{2}{*}{$P$ value } \\
\hline & \multicolumn{2}{|c|}{$(n=369)$} & \multicolumn{2}{|c|}{$(n=246)$} & \multicolumn{2}{|c|}{$(n=123)$} & \\
\hline Age at vitamin D draw date (years) & 80.36 & \pm 8.62 & 80.31 & \pm 8.61 & 80.46 & \pm 8.67 & 0.88 \\
\hline \multicolumn{8}{|l|}{ Charlson Comorbidity Index } \\
\hline Severity weighted sum of diseases & 5.67 & \pm 4.09 & 5.02 & \pm 3.92 & 6.97 & \pm 4.13 & $<0.001$ \\
\hline Severity and age weighted sum of disease & 9.23 & \pm 4.19 & 8.57 & \pm 4.13 & 10.54 & \pm 4.03 & $<0.001$ \\
\hline 25-hydroxyvitamin D (ng/mL) & 33.85 & \pm 19.07 & 35.32 & \pm 21.51 & 30.92 & \pm 12.46 & 0.037 \\
\hline From first vitamin D date to last follow-up (days) & 1276.38 & \pm 757.5 & 1231.72 & $\pm 7 \mid 8.57$ & 1365.69 & \pm 825.87 & 0.11 \\
\hline $\begin{array}{l}\text { From vitamin } D \text { date to pressure ulcer or } \\
\text { last follow-up (days) }\end{array}$ & 894.73 & \pm 677.53 & 1043.93 & \pm 625.44 & 596.35 & \pm 681.52 & $<0.001$ \\
\hline From last vitamin D date to last follow-up (days) & 1065.40 & \pm 654.62 & 1043.93 & \pm 625.44 & I I08.36 & \pm 710.12 & 0.37 \\
\hline Male gender, n (\%) & $|4|$ & $38 \%$ & 94 & $38 \%$ & 47 & $38 \%$ & 1 \\
\hline 25-hydroxyvitamin D $<25, \mathrm{n}(\%)$ & 86 & $23 \%$ & 48 & $20 \%$ & 38 & $31 \%$ & 0.015 \\
\hline Myocardial infarction, n (\%) & 91 & $25 \%$ & 51 & $21 \%$ & 40 & $33 \%$ & 0.013 \\
\hline Congestive heart failure, $\mathrm{n}(\%)$ & 139 & $38 \%$ & 73 & $30 \%$ & 66 & $54 \%$ & $<0.001$ \\
\hline Peripheral vascular disease, n (\%) & 108 & $29 \%$ & 63 & $26 \%$ & 45 & $37 \%$ & 0.029 \\
\hline Cerebrovascular disease, n (\%) & 173 & $47 \%$ & 107 & $43 \%$ & 66 & $54 \%$ & 0.07 \\
\hline Dementia, n (\%) & 23 & $6 \%$ & 18 & $7 \%$ & 5 & $4 \%$ & 0.22 \\
\hline Chronic pulmonary disease, n (\%) & 133 & $36 \%$ & 85 & $35 \%$ & 48 & $39 \%$ & 0.40 \\
\hline Ulcer, n (\%) & 113 & $31 \%$ & 72 & $29 \%$ & 41 & $33 \%$ & 0.42 \\
\hline Mild liver disease, n (\%) & 24 & $7 \%$ & 12 & $5 \%$ & 12 & $10 \%$ & 0.07 \\
\hline Diabetes, n (\%) & 97 & $26 \%$ & 50 & $20 \%$ & 47 & $38 \%$ & $<0.001$ \\
\hline Diabetic end organ damage, $n(\%)$ & 56 & $15 \%$ & 26 & $11 \%$ & 30 & $24 \%$ & $<0.001$ \\
\hline Hemiplegia, n (\%) & 25 & $7 \%$ & 12 & $5 \%$ & 13 & $11 \%$ & 0.04 \\
\hline Renal failure, n (\%) & 156 & $42 \%$ & 86 & $35 \%$ & 70 & $57 \%$ & $<0.001$ \\
\hline Moderate to severe liver disease, $n(\%)$ & 9 & $2 \%$ & 4 & $2 \%$ & 5 & $4 \%$ & 0.15 \\
\hline Metastatic disease, n (\%) & 48 & $13 \%$ & 32 & $13 \%$ & 16 & $13 \%$ & I \\
\hline Acquired immune deficiency syndrome, n (\%) & 0 & $0 \%$ & 0 & $0 \%$ & 0 & $0 \%$ & \\
\hline Rheumatoid arthritis, n (\%) & 59 & $16 \%$ & 37 & $15 \%$ & 22 & $18 \%$ & 0.48 \\
\hline Cancer, n (\%) & $17 \mid$ & $46 \%$ & 107 & $43 \%$ & 64 & $52 \%$ & 0.12 \\
\hline
\end{tabular}

and pressure ulceration became nonsignificant. This finding may represent a true lack of association of vitamin D levels and development of pressure ulcers. We also noted that this pilot study was underpowered to detect a difference between the two groups. All identified cases of pressure ulceration within the cohort were used for this case-control study. Thus, there still may be an association between vitamin D levels and pressure ulcers that was not detected by this study. These findings are novel and help to improve our understanding of pressure ulcers and the role of vitamin $\mathrm{D}$ in this disorder, despite the negative findings.

Malnutrition has been recognized as a risk factor for the onset and perpetuation of pressure sores, hence the interest in specific nutritional factors which impact ulcer development. Of the dietary factors, protein intake seems to be the most important. A low body mass index, low serum albumin, and weight loss are associated with an increased risk of pressure ulcers. ${ }^{19}$ Given the relationship between malnutrition and pressure ulceration, one might think that vitamin $\mathrm{D}$ deficiency may play a role in pressure ulcer development.
There are very few studies that have looked into the role of specific nutritional deficiencies. Unfortunately, there is no evidence in the literature looking specifically at vitamin D and pressure ulcers. Our study provides some first steps in the understanding of vitamin $\mathrm{D}$ and pressure ulceration despite the lack of statistical significance of its findings. The impact of vitamin D supplementation and pressure ulcer development is completely unknown.

Vitamin D deficiency has developed rapidly into a problem of considerable proportions in older adults, with $25 \%-50 \%$ of nursing home or housebound residents, $44 \%$ of elderly ambulatory women aged $>80$ years, and $57 \%$ of hospitalized adult patients (mean age 62 years) being vitamin D-deficient. ${ }^{16}$ During the past decade, major advances have been made in vitamin $\mathrm{D}$ research with regards to health in older adults. Vitamin D deficiency has been associated with many illnesses, including osteoporosis, falls, ${ }^{20}$ and frailty in the elderly. ${ }^{21}$ Importantly, vitamin D supplementation has been used in some disorders of the skin. Vitamin D analogs are being used routinely for psoriasis ${ }^{22}$ and other 
Table 4 Univariate analysis

\begin{tabular}{|c|c|c|c|c|}
\hline \multirow[t]{2}{*}{ Parameter } & \multirow[t]{2}{*}{ OR } & \multicolumn{2}{|l|}{$95 \% \mathrm{Cl}$} & \multirow[t]{2}{*}{$P$ value } \\
\hline & & Lower & Upper & \\
\hline Vitamin D & 0.98 & 0.96 & 0.98 & 0.0285 \\
\hline Vitamin $D<25$ & 1.87 & 1.12 & 3.10 & 0.0154 \\
\hline Charlson Comorbidity Index & 1.13 & 1.07 & 1.20 & $<0.0001$ \\
\hline Myocardial infarction & 1.94 & 1.16 & 3.25 & 0.0115 \\
\hline Congestive heart failure & 2.87 & 1.79 & 4.62 & $<0.0001$ \\
\hline Peripheral vascular disease & $\mathrm{I} .77$ & $\mathrm{I} .07$ & 2.90 & 0.0239 \\
\hline Cerebrovascular disease & 1.45 & 0.95 & 2.20 & 0.0798 \\
\hline Dementia & 0.54 & 0.19 & $\mathrm{I} .48$ & 0.2346 \\
\hline Chronic pulmonary disease & $\mathrm{I} .2 \mathrm{I}$ & 0.77 & 1.89 & 0.3994 \\
\hline Ulcer & 1.20 & 0.75 & 1.92 & 0.4239 \\
\hline Mild liver disease & 2.07 & 0.90 & 4.72 & 0.0832 \\
\hline Diabetes & 2.70 & 1.59 & 4.60 & 0.0002 \\
\hline $\begin{array}{l}\text { Diabetes with end } \\
\text { organ damage }\end{array}$ & 3.17 & 1.65 & 6.10 & 0.0005 \\
\hline Hemiplegia & 2.52 & 1.05 & 6.03 & 0.0368 \\
\hline Renal & 2.70 & 1.67 & 4.39 & $<0.0001$ \\
\hline $\begin{array}{l}\text { Moderate to severe } \\
\text { liver disease }\end{array}$ & 2.50 & 0.67 & 9.31 & 0.1720 \\
\hline Metastatic & 1.00 & 0.53 & 1.88 & 1.0000 \\
\hline Rheumatoid arthritis & 1.24 & 0.68 & 2.24 & 0.4756 \\
\hline Cancer & 1.44 & 0.91 & 2.27 & 0.1107 \\
\hline
\end{tabular}

Abbreviations: $\mathrm{Cl}$, confidence interval; OR, odds ratio.

skin disorders. Vitamin D analogs are highly effective agents in this disorder. ${ }^{23}$

Comorbid medical illness measured by the Charlson Comorbidity Index was associated with increased risk of pressure ulceration. For every point increase in Charlson Comorbidity Index, the risk of pressure ulceration increased by $14 \%$. Other investigators have also found a relationship between comorbid illness and pressure ulcers. Margolis et al found an association between comorbid medical conditions and pressure ulcers in older ambulatory patients. They found that congestive heart failure, Alzheimer's disease, chronic obstructive pulmonary disease, cerebrovascular accident, limb paralysis, lower limb edema, malignancy, malnutrition, osteoporosis, deep venous thrombosis, Parkinson's disease, rheumatoid arthritis, hip fracture, hip surgery, and urinary tract infections were associated with development of a pressure ulcer. ${ }^{24}$ Our findings make sense pathophysiologically. Patients with significant comorbid illnesses are likely to be immobile and

Table 5 Multivariate model

\begin{tabular}{lll}
\hline Multivariate model & OR & P value \\
\hline Vitamin D & 0.985 & 0.0892 \\
Charlson Comorbidity Index & 1.129 & $<0.000$ I \\
Vitamin D $<25$ & 1.627 & 0.0730 \\
Charlson Comorbidity Index & 1.128 & $<0.000 \mathrm{I}$ \\
\hline
\end{tabular}

Abbreviation: OR, odds ratio. may suffer from urinary or fecal incontinence which would place the patient at further risk for ulceration.

There are limitations to this initial matched case-control study. One limitation is the retrospective case-control design and data. Administrative data systems suffer inherent weaknesses, including potential missing or miscoded information. Some of the data challenges are minimized in this study because the Mayo Clinic maintains a robust data system and comprehensive electronic medical records that collect demographic, medical utilization, and comorbidity health data. A second concern involves the incident diagnosis of pressure ulceration. It is possible that some patients developed pressure ulceration and did not seek medical attention, so the type of pressure ulcers may have been more severe or recalcitrant. This case-control study was drawn from a cohort of patients with a pre-existing vitamin $\mathrm{D}$ level measurement, so it is possible that this cohort may differ from a cohort without a vitamin D level drawn. In our study, the 25-hydroxyvitamin D levels were drawn considerably earlier than the development of pressure ulceration. 25-hydroxyvitamin D has a serum half-life of 2-3 weeks, so the vitamin $\mathrm{D}$ level at the time of ulcer development may differ from the drawn level. The study was conducted in a population of primarily Northern Europeans in a northern US state, so the ability to generalize this study beyond Olmsted County may be limited. Due to the retrospective nature of our study, we did not have information on protein energy nutritional status or other nutritional indicators which may have acted as confounders. Thus, vitamin D deficiency may act as a marker for nutritional deficiency. We did not have a standardized pressure ulcer predictor instrument available for these ambulatory outpatients, so we used the Charlson Comorbidity Index as a means of adjusting for patients at risk of pressure ulceration. Lastly, this study was underpowered to detect fully a difference after adjustment. It was encouraging that the univariate findings did show a difference, and should provide some impetus for further work. Despite the study limitations, the relationship between vitamin $\mathrm{D}$ and pressure ulcers needs further explanation and exploration.

\section{Conclusion}

Vitamin D deficiency was not associated with pressure ulceration in this matched case-control study after adjustment for comorbid medical illness. Vitamin D deficiency and vitamin D levels were associated with pressure ulcers in univariate analysis. Subjects with multiple comorbid conditions had an increased risk of pressure ulcers. This was a pilot study and was underpowered to detect a difference 
between the groups, so this could explain the lack of association. Vitamin D levels may also serve as a surrogate for health conditions, with worsening health associated with lower vitamin D levels. Despite the negative findings, more studies are still needed for better evaluation of the role of vitamin $\mathrm{D}$ in pressure ulceration. Vitamin D deficiency is easy to treat with replacement therapy, hence the importance of understanding fully the relationship between the two conditions.

\section{Acknowledgment}

This research was supported by a National Institutes of Health National Center for Research Resources Clinical and Translational Science Awards grant.

\section{Disclosure}

The authors report no conflicts of interest in this work.

\section{References}

1. Lyder CH. Pressure ulcer prevention and management. JAMA. 2003; 289:223-226.

2. Staas WE Jr, Cioschi HM. Pressure sores - a multifaceted approach to prevention and treatment. West J Med. 1991;154:539-544.

3. Graves N, Birrell F, Whitby M. Effect of pressure ulcers on length of hospital stay. Infect Control Hosp Epidemiol. 2005;26:293-297.

4. Berlowitz DR, Brandeis GH, Anderson J, Du W, Brand H. Effect of pressure ulcers on the survival of long-term care residents. J Gerontol A Biol Sci Med Sci. 1997;52:M106-M110.

5. Thomas DR, Goode PS, Tarquine PH, Allman RM. Hospitalacquired pressure ulcers and risk of death. J Am Geriatr Soc. 1996;44: $1435-1440$.

6. Brumbaugh PF, Haussler MR. Nuclear and cytoplasmic binding components for vitamin D metabolites. Life Sci. 1975;16:353-362.

7. Kream BE, Reynolds RD, Knutson JC, Eisman JA, DeLuca HF. Intestinal cytosol binders of 1,25-dihydroxyvitamin D and 25-hydroxyvitamin D. Arch Biochem Biophys. 1976;176:779-787.

8. Plum LA, DeLuca HF. Vitamin D, disease and therapeutic opportunities. Nat Rev Drug Discov. 2010;9:941-955.
9. Krämer C. Characterization of the vitamin D endocrine system in human sebocytes in vitro. J Steroid Biochem Mol Biol. 2009;113:9-16.

10. Stumpf WE, Sar M, Reid FA, Tanaka Y, DeLuca HF. Target cells for 1,25-dihydroxyvitamin D3 in intestinal tract, stomach, kidney, skin, pituitary and parathyroid. Science. 1979;206:1188-1190.

11. Simpson RU, DeLuca HF. Characterization of a receptor-like protein for 1,25-dihydroxyvitamin D3 in rat skin. Proc Natl Acad Sci U S A. 1980;77:5822-5826.

12. Hosomi J, Hosoi J, Abe E, Suda T, Kuroki T. Regulation of terminal differentiation of cultured mouse epidermal cells by $1 \alpha, 25-$ dihydroxyvitamin D3. Endocrinology. 1983;113:1950-1957.

13. Rickham PP. Human experimentation. Code of Ethics of the World Medical Association. Declaration of Helsinki. BMJ. 1964;2:177.

14. US Census Bureau. US Census. Available at: http://www.census.gov. Accessed May 10, 2011.

15. Melton LJ 3rd. History of the Rochester Epidemiology Project. Mayo Clin Proc. 1996;71:266-274.

16. Kennel KA, Drake MT, Hurley DL. Vitamin D deficiency in adults: when to test and how to treat. Mayo Clin Proc. 2010;85:752-757.

17. Sundararajan V, Henderson T, Perry C, Muggivan A, Quan H, Ghali WA. New ICD-10 version of the Charlson comorbidity index predicted in-hospital mortality. J Clin Epidemiol. 2004;57:1288-1294.

18. Charlson ME, Pompei P, Ales KL, MacKenzie CR. A new method of classifying prognostic comorbidity in longitudinal studies: development and validation. J Chronic Dis. 1987;40:373-383.

19. Fontaine J, Raynaud-Simon A. Pressure sores in geriatric medicine: the role of nutrition. Presse Med. 2008;37:1150-1157. French.

20. Bischoff HA, Stahelin HB, Dick W, et al. Effects of vitamin D and calcium supplementation on falls: a randomized controlled trial. J Bone Miner Res. 2003;18:343-351.

21. Wilhelm-Leen ER, Hall YN, Deboer IH, Chertow GM. Vitamin D deficiency and frailty in older Americans. $J$ Intern Med. 2010;268: 171-180.

22. Kragballe K. Treatment of psoriasis with calcipotriol and other vitamin D analogues. J Am Acad Dermatol. 1992;27:1001-1008.

23. Barker JN, Ashton RE, Marks R, Harris RI, Berth-Jones J. Topical maxacalcitrol for the treatment of psoriasis vulgaris: a placebo-controlled, double-blind, dose-finding study with active comparator. Br J Dermatol. 1999;141:274-278.

24. Margolis DJ, Knauss J, Bilker W, Baumgarten M. Medical conditions as risk factors for pressure ulcers in an outpatient setting. Age Ageing. 2003;32:259-264.
Clinical Interventions in Aging

\section{Publish your work in this journal}

Clinical Interventions in Aging is an international, peer-reviewed journal focusing on evidence-based reports on the value or lack thereof of treatments intended to prevent or delay the onset of maladaptive correlates of aging in human beings. This journal is indexed on PubMed Central, MedLine, the American Chemical Society's 'Chemical

\section{Dovepress}

Abstracts Service' (CAS), Scopus and the Elsevier Bibliographic databases. The manuscript management system is completely online and includes a very quick and fair peer-review system, which is all easy to use. Visit http://www.dovepress.com/testimonials.php to read real quotes from published authors. 